\title{
Optimising Drug Solubilisation in Amorphous Polymer Dispersions: Rational Selection of Hot-melt Extrusion Processing Parameters
}

\author{
Shu Li, ${ }^{1}$ Yiwei Tian, ${ }^{1}$ David S. Jones, ${ }^{1}$ and Gavin P. Andrews ${ }^{1,2}$
}

Received 4 August 2015; accepted 21 October 2015; published online 4 January 2016

\begin{abstract}
The aim of this article was to construct a T- $\phi$ phase diagram for a model drug (FD) and amorphous polymer (Eudragit ${ }^{\circ} \mathrm{EPO}$ ) and to use this information to understand the impact of how temperature-composition coordinates influenced the final properties of the extrudate. Defining process boundaries and understanding drug solubility in polymeric carriers is of utmost importance and will help in the successful manufacture of new delivery platforms for BCS class II drugs. Physically mixed felodipine (FD)-Eudragit ${ }^{\circledR}$ EPO (EPO) binary mixtures with pre-determined weight fractions were analysed using DSC to measure the endset of melting and glass transition temperature. Extrudates of $10 \mathrm{wt} \% \mathrm{FD}-\mathrm{EPO}$ were processed using temperatures $\left(110^{\circ} \mathrm{C}, 126^{\circ} \mathrm{C}, 140^{\circ} \mathrm{C}\right.$ and $\left.150^{\circ} \mathrm{C}\right)$ selected from the temperaturecomposition $(\mathrm{T}-\phi)$ phase diagrams and processing screw speed of 20, 100 and 200rpm. Extrudates were characterised using powder X-ray diffraction (PXRD), optical, polarised light and Raman microscopy. To ensure formation of a binary amorphous drug dispersion (ADD) at a specific composition, HME processing temperatures should at least be equal to, or exceed, the corresponding temperature value on the liquid-solid curve in a F-H T- $\phi$ phase diagram. If extruded between the spinodal and liquid-solid curve, the lack of thermodynamic forces to attain complete drug amorphisation may be compensated for through the use of an increased screw speed. Constructing F-H T- $\phi$ phase diagrams are valuable not only in the understanding drug-polymer miscibility behaviour but also in rationalising the selection of important processing parameters for HME to ensure miscibility of drug and polymer.
\end{abstract}

KEY WORDS: DSC; Flory-Huggins theory; hot-melt extrusion; thermal processing.

\section{INTRODUCTION}

Drug solubilisation strategies have become ever more important over the past two decades, primarily due to the increased occurrence of new chemical entities (NCEs) that are poorly soluble but highly permeable (BCS class II) (1). These drug molecules have a therapeutic efficacy that is limited by solubility and often require enabling technologies in order to become viable, efficacious drug delivery systems. Among the strategies employed, there has been significant interest in amorphous drug dispersions (ADDs) (2). Relative to their crystalline counterparts, amorphous drug forms typically exhibit a significantly higher apparent solubility and a faster dissolution rate. Furthermore, dispersion of the amorphous drug into a polymer matrix can provide a physical barrier to aggregation of drug particles and reduce the risk of physical change post manufacture. In particular, dispersion of drug at the molecular level is desirable from both a

\footnotetext{
${ }^{1}$ Pharmaceutical Engineering Group, School of Pharmacy, Medical Biology Centre, Queen's University, Belfast, BT9 7BL, Northern Ireland, UK.

${ }^{2}$ To whom correspondence should be addressed. (e-mail: g.andrews@qub.ac.uk)
}

solubility enhancement and physical stability perspective. Hot melt extrusion (HME) technology has been shown to be a robust method for manufacturing amorphous drug dispersions and has several advantageous over other commonly used techniques (e.g. spray-drying). HME is regarded as a continuous manufacturing method and has capability for ease of scaleup. Moreover, it is a solvent-free process, offers the possibility of processing at a range of extrusion conditions (e.g. temperature, screw design and feed rate) and permits the introduction of process analytical technologies and adoption of 'Quality by Design' ( $\mathrm{QbD}$ ) principles. In general, processing temperatures in the melting zone of an extruder should be at least $15 \sim 60^{\circ} \mathrm{C}$ above the glass transition temperature $\left(T_{\mathrm{g}}\right)$ or the melting temperature $\left(T_{\mathrm{m}}\right)$, of polymeric excipients, in order to attain suitable plasticity and hence enable melt flow within the extruder barrel $(3,4)$. Likewise, when taking into account the relatively short residence time associated with HME processing, it is usually recommended to extrude the raw materials $15 \sim 30^{\circ} \mathrm{C}$ above the $T_{\mathrm{m}}$ of the drug substance to guarantee complete amorphisation of the drug and subsequently adequate mixing with the polymeric matrix (5). Therefore, high-melting drug substances often require high processing temperatures and an associated risk of thermal degradation for both drug and polymer. 
A recent review of drug candidates developed over the last 10 years has shown that these compounds "differ significantly from those of historical leads" in the sense that there is an increased number of heavy atoms, rotors and ring structures (6). Such additional complexity may result in an increased sensitivity to thermal degradation, and consequently, the need to identify suitable non-ambient processing conditions is a growing necessity. There are numerous examples wherein crystalline drugs dissolve into the molten polymer matrix below the drug $T_{\mathrm{m}}$ and form amorphous dispersions. In those cases, dissolution of drug is dependent on the miscibility and intermolecular interactions between the drug and polymer (5,7-11). It is obvious therefore that a clear understanding of miscibility across a wide range of temperatures is necessary in order to promote drug solubilisation and molecular dispersion of drug in polymer at minimal processing conditions. With this knowledge, extrusion conditions may be selected to promote formation of molecular dispersions whilst also avoiding drug and/or polymer degradation.

It is evident that an in-depth understanding of drugpolymer miscibility is essential, and the prediction of miscibility in advance of processing can assist formulation development. A number of recent publications have successfully defined the mixing behaviour of drug-polymer binary mixtures from a thermodynamic perspective (12-15). Our group has also published a series of articles, utilising Flory-Huggins $(\mathrm{F}-\mathrm{H})$ theory in combination with the measurement of melting temperature depression to understand drug-polymer phase behaviour (16-18). In doing so, thermodynamic miscibility is expressed as a temperature/composition phase diagram, whilst Gibb's free energy of mixing may be expressed as a function of both temperature and composition. A typical $\mathrm{F}-\mathrm{H}$ temperature-composition $(\mathrm{T}-\phi)$ phase diagram depicts six miscibility zones divided by three curves, the liquid-solid curve, the spinodal decomposition curve and the $T_{\mathrm{g}}$ curve, respectively (16).

Using these regions, the definition of processing temperatures and drug volume fractions that would be most likely to generate miscible drug-polymer systems (ignoring kinetic effects) becomes much more obvious. For example, a drugpolymer system positioned (defined by temperature and drug volume fraction) within the miscible region would be expected to generate a homogeneous phase that is thermodynamically favoured. In contrast, if processed in an unstable region, phase separation would be thermodynamically favoured. It is reasonable to hypothesise that solubility curves may be used to depict the lowest suitable processing temperature for preparation of molecular drug dispersions. Therefore, in this article, it is our primary aim to construct $\mathrm{T}-\phi$ phase diagrams for a model binary system (felodipine/EPO) and, subsequently, melt extrude binary mixtures using temperatures-composition coordinates from various regions. This will provide an improved understanding of how thermodynamic considerations can be used in the manufacture of solid dispersions using nonambient processes such as HME. Moreover, the determination of a minimum processing temperature may be particularly useful for chemical entities that are more prone to thermal degradation. Additionally, during hot-melt extrusion, mixing behaviour is not solely dependent upon temperature. It has been shown that drug dissolution within polymeric carriers can be enhanced by both elevated temperature and screw speed (19). A secondary aim of this work is to investigate the role of screw speed and how it may be aligned with the processing temperature to manufacture optimised drug-polymer molecular dispersions.

\section{MATERIALS AND METHODOLOGY}

\section{Materials}

Felodipine (FD), a dihydropyridine calcium channel blocker (CCB), was a generous gift from AstraZeneca (Macclesfield, UK). Eudragit ${ }^{\circledR}$ E PO (EPO), a copolymer composed of neutral methyl and butyl methacrylic acid esters and dimethylaminoethyl methacrylate repeating units, was kindly provided as a free sample by Evonik Industries AG (Darmstadt, Germany).

\section{Methodology}

\section{Thermal Analysis}

FD and EPO were individually pulverised and sieved to a $53 \sim 90-\mu \mathrm{m}$ size range. The binary physical mixtures that consisted of FD and EPO were prepared through careful mixing of the powdered components using a mortar and pestle at pre-determined FD loadings. Melting point depression experiments on the binary physical mixtures were conducted on a DSC 8000 power compensation differential scanning calorimeter (Perkin-Elmer, Windsor, Berkshire, UK). The instrument was calibrated at the respective ramp rate with indium and zinc for both melting point and heat of fusion. Dry nitrogen was purged at a flow rate of $40 \mathrm{~mL} \mathrm{~min}^{-1}$ through the sample and reference cells to maintain an inert atmosphere. Three to five milligrammes of sample was accurately weighed into aluminium pans and crimped using an aluminium pan lid. The crimped pan set was then equilibrated at $100^{\circ} \mathrm{C}$ for $60 \mathrm{~min}$ followed by a thermal ramp at $1^{\circ} \mathrm{C} \mathrm{min}^{-1}$ to $180^{\circ} \mathrm{C}$. Plots of the heat flow $(\mathrm{W} / \mathrm{g})$ versus temperature were recorded and analysed using Pyris (version 10.1.0.0412) software. The endset of melting was calculated from the DSC thermogram as the intersection of the falling edge of the melting endotherms and the post-melting baseline. The fused samples from the melting point measurement experiments were air-cooled to ambient temperature and subsequently subjected to modulated DSC (TA Q100, TA Instruments) to be heated for a second time at $2^{\circ} \mathrm{C} \mathrm{min}{ }^{-1}$, with an amplitude and frequency of $\pm 0.6^{\circ} \mathrm{C}$ every $40 \mathrm{~s}$ to enable the determination of $T_{\mathrm{g}}$.

\section{Treatment of Data and Construction of Phase Diagram}

The use of Flory-Huggins lattice theory to construct a T$\phi$ phase diagram thus determining drug-polymer solubility as a function of temperature has been well established in the current literature (13-18,20,21). Accordingly, Gibb's free energy of mixing $\Delta G_{\text {mix }}$ can be expressed as (22):

$$
\frac{\Delta G_{\mathrm{mix}}}{R T}=\phi \ln \phi+\frac{(1-\phi)}{m} \ln (1-\phi)+\chi \phi(1-\phi)
$$

where $R$ is the gas constant, $\phi$ is the volume fraction of drug, $m$ is the volume ratio of a polymer chain to a lattice site, $T$ is 
the Kelvin temperature and $\chi$ is the $\mathrm{F}-\mathrm{H}$ interaction parameter. Negative $\chi$ values indicate favoured interspecies miscibility, whereas positive values suggest immiscibility. It has been reported that the dependence of $\chi$ as a function of temperature may be simplified as follows $(16,23)$ :

$\chi=A+\frac{B}{T}$

where constants $A$ and $B$ represent the entropic and enthalpic contributions, respectively. In addition, the extended Flory expression of the theory of melting point depression allows the calculation of the $\mathrm{F}-\mathrm{H}$ interaction parameter $\chi$ at varying drug fractions (21,24-26):

$\chi=\frac{\frac{1}{T_{\mathrm{m}}}-\frac{1}{T_{\mathrm{m}}^{0}}}{-\frac{R}{\Delta H}(1-\phi)^{2}}-\frac{\ln \phi}{(1-\phi)^{2}}-\frac{1-\frac{1}{m}}{1-\phi}$

where $T_{\mathrm{m}}{ }^{0}$ is the melting point of the pure drug, $T_{\mathrm{m}}$ is the depressed drug melting point at particular drug-polymer fractions, $\Delta H$ is the enthalpy of fusion of the pure drug. Therefore, constants $A$ and $B$ in Eq. 2 may be fitted using experimentally obtained $T_{\mathrm{m}}$ and the calculated $\chi$ according to Eq. 3. Subsequently, by substituting Eq. 2 back into Eq. 1, Gibb's free energy of mixing expression can be converted to

$\frac{\Delta G_{\mathrm{mix}}}{R T}=\phi \ln \phi+\frac{1-\phi}{m} \ln (1-\phi)+(1-\phi)\left(A+\frac{B}{T}\right)$

The spinodal decomposition curve is obtained by setting the second derivative of the free energy of mixing expression (Eq. 4) with respect to the drug volume fraction to zero:

$T_{\mathrm{s}}=\frac{2 B}{\frac{1}{\phi}+\frac{1}{m(1-\phi)}-2 A}$

\section{Preparation of Hot-melt Extrudates}

FD was mixed with EPO at a drug-polymer weight fraction of 1:9 using a mortar and pestle. The prepared physical mixtures (PMs) were manually fed into a co-rotating conical twin-screw extruder (HAAKE Minilab, Thermo Electron Corporation, Stone, Staffordshire, UK). All extrusions were conducted in triplicate to measure the mean residence time and processing torque. The binary mixture was subjected to four processing temperatures, respectively, and three screw speeds: 20, 100 and $200 \mathrm{rpm}$, respectively. The four processing temperatures were selected according to the $\mathrm{T}-\phi$ phase diagrams as follows: a low temperature from the unstable region $\left(T_{\mathrm{L}}=110^{\circ} \mathrm{C}\right)$, the boundary temperature on the spinodal curve for $10 \mathrm{wt} \% \mathrm{FD}$ loading $\left(T_{\mathrm{B} 1}=126^{\circ} \mathrm{C}\right)$, the boundary temperature on the liquid-solid curve for $10 \mathrm{wt} \%$ FD loading $\left(T_{\mathrm{B} 2}=140^{\circ} \mathrm{C}\right)$ and a high temperature from the miscible region $\left(T_{\mathrm{H}}=150^{\circ} \mathrm{C}\right)$. Rod-shaped extrudates were immediately pelletized (Thermo Fisher Scientific, Stone, Staffordshire, UK) to a $2.0 \mathrm{~mm}$ length and then vacuum desiccated at room temperature overnight prior to further tests. The extrusion parameters used during manufacture are listed in Table I.

\section{Powder X-ray Diffraction}

A MiniFlex II desktop powder X-ray diffractometer (Rigaku Corporation, Japan) equipped with Ni-filtered, $\mathrm{Cu}$ $\mathrm{K} \beta$ radiation, at a voltage of $30 \mathrm{kV}$ and a current of $15 \mathrm{~mA}$ was employed to characterise crystallinity in raw materials, physical mixtures and hot-melt extrudates. The samples were pulverised in a ball mill chamber using a frequency of $25 \mathrm{~s}^{-1}$ for $30 \mathrm{~s}$. The powdered sample was placed on a glass toploading holder with a $0.2 \mathrm{~mm}$ depression and gently consolidated. All samples were scanned within the angular range $3-$ $40^{\circ} 2 \theta$ in continuous mode with a sample width of $0.03^{\circ}$ and a scan speed of $2.0^{\circ} \mathrm{min}^{-1}$.

\section{Microscopic Analysis}

Optical micrographs were taken to examine the morphology of the FD-EPO melt extrudates. The equipment used was a Leica EZ4 D stereo zoom microscope (Leica Microsystems Ltd., Buckinghamshire, UK). The sample was illuminated with LED light and pictured using a $\times 25$ magnification. Polarised light microscopy (PLM, Olympus BX50F4, Microscope Service and Sales, Surrey, UK) was used to identify the presence of residual crystalline FD in the extruded EPO matrices. A polarised light micrograph of each sample was captured at room temperature using a PixeLINK Megapixel FireWire camera and PixeLINK software (Scorpion Vision Ltd., Lymington, UK). Crystalline FD was observed as bright and colourful particles within the cross-sectional area of the sample. All measurements were performed with a magnification of $\times 40$.

\section{Raman Mapping Analysis}

Raman spectroscopy analysis was conducted using a RamanMicro 300 Raman microscope (Perkin Elmer, Windsor, Berkshire, UK) coupled with an Avalon Raman station R3 model AVRS003A spectrometer (Avalon Instruments, Belfast, UK). A magnification of $\times 20$ and a total exposure time of $20 \mathrm{~s}$ ( $4 \mathrm{~s}$ acquisition $\times 5$ were used for all samples). Data was collected across $200-3200 \mathrm{~cm}^{-1}$ wave numbers using an automatic baseline correction and analysed using Spectrum v6.3.4 software. Cross sections of the extruded pellets were mapped (Raman microscope) using $0.05 \mathrm{~mm}$ spacing between each sampling point. Laser power was set at $70 \%$ throughout the mapping process to avoid sample saturation. Spectrum IMAGE R1.6.4.0394 software was used to correlate the spectrum of each individual pixel from the mapped cross sections with the reference spectrum obtained from a crystalline FD powder bed. The Raman shift range of $[1720 \sim 1600] \mathrm{cm}^{-1}$ was employed for pixel/reference comparison in the compare correlation mode. The maps were shown within the correlation coefficient scale from 0.676 to 1.001. A rainbow cubic look-up table was utilised to illustrate the degree of correlation. 
Table I. Formulation Nomenclature, HME Processing Data and Product Visual Assessment of All Melt Extruded Samples

\begin{tabular}{|c|c|c|c|c|c|c|c|c|c|}
\hline Formulation & $\begin{array}{l}\text { FD loading } \\
(\%)\end{array}$ & $\begin{array}{l}T_{\text {proc }} \\
{ }^{\circ} \mathrm{C}\end{array}$ & & & & $\begin{array}{l}\text { Screw speed } \\
(\mathrm{rpm})\end{array}$ & $\begin{array}{l}\text { Torque } \\
(\mathrm{Ncm})\end{array}$ & $\begin{array}{l}\text { Residence time } \\
\text { (s) }\end{array}$ & Visual assessment \\
\hline \multirow[t]{4}{*}{ Low screw speed } & 10 & 110 & - & - & - & 20 & $30 \pm 2$ & $434 \pm 36$ & Visible crystals \\
\hline & 10 & - & 126 & - & - & 20 & $16 \pm 1$ & $110 \pm 1$ & Visible crystals (less) \\
\hline & 10 & - & - & 140 & - & 20 & $8 \pm 1$ & $89 \pm 3$ & Clear strands \\
\hline & 10 & - & - & - & 150 & 20 & $6 \pm 1$ & $92 \pm 2$ & Clear strands \\
\hline \multirow[t]{4}{*}{ Medium screw speed } & 10 & 110 & - & - & - & 100 & $122 \pm 4$ & $140 \pm 1$ & Visible crystals \\
\hline & 10 & - & 126 & - & - & 100 & $66 \pm 2$ & $81 \pm 1$ & Shattered crystals \\
\hline & 10 & - & - & 140 & - & 100 & $34 \pm 5$ & $54 \pm 1$ & Clear strands \\
\hline & 10 & - & - & - & 150 & 100 & $30 \pm 1$ & $46 \pm 4$ & Clear strands \\
\hline \multirow[t]{4}{*}{ High screw speed } & 10 & 110 & - & - & - & 200 & $155 \pm 7$ & $122 \pm 8$ & Shattered crystals (less) \\
\hline & 10 & - & 126 & - & - & 200 & $78 \pm 4$ & $40 \pm 2$ & Shattered crystals (little) \\
\hline & 10 & - & - & 140 & - & 200 & $60 \pm 4$ & $24 \pm 1$ & Clear strands \\
\hline & 10 & - & - & - & 150 & 200 & $49 \pm 3$ & $22 \pm 1$ & Clear strands \\
\hline
\end{tabular}

The processing torque and residence time tabulated are the mean of three individual extrusions \pm standard deviation. Residence times are the minimum residence time at which the first trace of extrudate exited the die

\section{Statistical Analysis}

Statistical analyses were conducted using a one-way analysis of variance (GraphPad Prism 6.0). Individual differences between treatment groups were identified using Tukey's post hoc test with $P<0.05$ denoting significance.

\section{RESULTS AND DISCUSSION}

\section{Melting Point Depression Measurements and the Construction of Phase Diagrams}

Previously, our group employed an 8 min milling cycle (16-18) in preparing physical mixtures of drug and polymer. Intimate mixing of raw materials prior to extrusion is an ideal scenario but not always the case in practice. In an attempt to avoid partial amorphorisation of drug by milling and hence overestimate the HME processing window, fine powders (53$90 \mu \mathrm{m})$ of the pulverised components were carefully mixed in precise weight fractions using a mortar and pestle. However, it was also crucial that the mixed samples were given adequate time during DSC experiments for drug dissolution. Therefore, a $60 \mathrm{~min}$ isotherm was introduced at $100^{\circ} \mathrm{C}$, an intermediate temperature between the $T_{\mathrm{g}}$ of EPO and the $T_{\mathrm{m}}$ of FD, and the heating rate for DSC experiments was set at $1^{\circ} \mathrm{C} \mathrm{min}^{-1}$.

$\Delta G_{\text {fus }}$ is usually expressed as the combination of both enthalpic and entropic contributions to a system: $\Delta G_{\text {fus }}=\Delta H_{\text {fus }}-T \Delta S$. At the melting point, the solid and liquid phases coexist in equilibrium, the free energy of fusion $\Delta G_{\text {fus }}$ then equals zero and the melting point may be expressed as $T_{\mathrm{m}}=\Delta H / \Delta S$. At the isothermal temperature, EPO is present as a viscous melt, whilst FD remains solid. If FD is somewhat soluble in the EPO melt pool, the solubilised portion will possess increased randomness relative to the solid drug portion and hence increased entropy. When subsequently heated, the enthalpy ought to be decreased as the solubilised FD portion should no longer be a factor to influence heat absorption. These translate to the depression of both $T_{\mathrm{m}}$ and $\Delta H$ (27), and such depression increases as the EPO fraction increases. If FD-EPO system is completely immiscible, phase separation occurs; hence, neither enthalpy- nor entropydriven melting point depression should occur.

Figures 1 and 2 illustrate the influence of EPO polymer fraction on both the $T_{\mathrm{m}}$ and $\Delta H$ of FD. It can also be observed from data presented in Table II that the $T_{\mathrm{m}}$ and $\Delta H$ of FD both decreased as the EPO loading within the formulation was increased. The decrease of $T_{\mathrm{m}}$ relative to pure FD only became statistically significant when $25 \mathrm{wt} \%$ or more EPO was introduced to the system $(P<0.01$ for FD loadings 75, 70 and $65 \mathrm{wt} \%$ ). For example, the addition of $35 \mathrm{wt} \%$ EPO depressed FD $T_{\mathrm{m}}$ from $145.88 \pm 0.02^{\circ} \mathrm{C}$ to $144.31 \pm 0.09^{\circ} \mathrm{C}$. The decrease of $\Delta H$, on the other hand, was significant from as low as only $5 \mathrm{wt} \%$ EPO incorporation $(P<0.05)$. The $\Delta H$ measurement and extrapolation of experimental values using linear regression suggested that approximately $35 \mathrm{wt} \%$ of FD could be solubilised in an EPO melt at or close to the melting point of FD. The depressed $T_{\mathrm{m}}$ was used to calculate the F-H interaction parameter $\chi$ for FD loadings from 95 to $65 \mathrm{wt} \%$ according to Eq. 3 (Table II). The obtained $\chi$ values were then plotted against the corresponding $1 / T_{\mathrm{m}}$ values in Fig. 3. Linear regression of $\chi$ versus $1 / T$ plot had a high correlation coefficient $(>0.99)$ and hence confirmed the linear dependence in Eq. 2, enabling the calculation of entropic $(A)$ and enthalpic $(B)$ contributions to $\chi$ in the FD-EPO system. In agreement with our previous work, positive values of the calculated $B$ term indicated upper critical solution temperature (UCST) behaviour and corresponded to decreasing $\chi$ values with increasing temperature (18). The calculated values for constants $A$ $(-126.557)$ and $B(53038.616)$ were subsequently used in Eq. 4 to construct the T- $\phi$ phase diagram (Fig. 4).

A $T_{\mathrm{g}}$ curve is typically shown in a complete $\mathrm{F}-\mathrm{H}$ phase diagram to signify a region where viscosity of the system increases so dramatically that mixing becomes kinetically hindered over experimentally feasible time scales $(28,29)$. In accordance with the literature (30), the $T_{\mathrm{g}}$ values for FD and EPO were observed to be extremely close to each other at $46.65 \pm 0.44^{\circ} \mathrm{C}$ and $46.76 \pm 0.60^{\circ} \mathrm{C}$, respectively. It was also observed that the $T_{\mathrm{g}}$ of EPO decreased on the second heating curve relative to the first heating curve $\left(55.57 \pm 0.23^{\circ} \mathrm{C}\right)$, presumably owing to removal of thermal history through heatcool treatment (31). According to Gordon-Taylor equation, if 


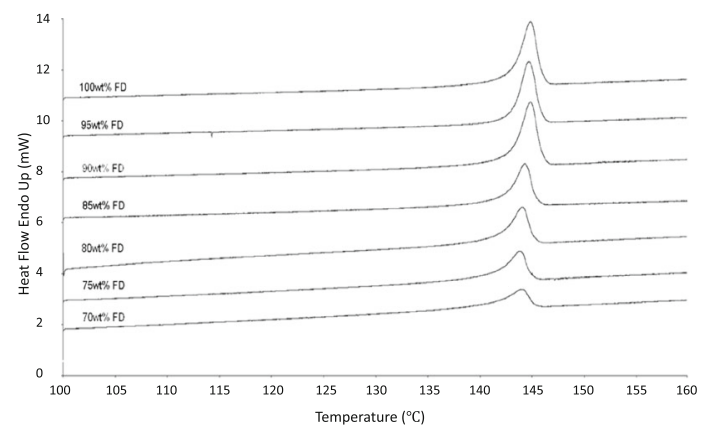

Fig. 1. Thermograms of FD-EPO physical mixtures heated at $1^{\circ} \mathrm{C} \min ^{-1}$. The labels above each curve indicate the FD loading (weight fraction) in the physical mixture

FD and EPO are miscible at a certain ratio, there should exist a single $T_{\mathrm{g}}$ somewhere between the individual $T_{\mathrm{g}} \mathrm{s}$ of the two components when mixed at such a ratio. Given the fact that the $T_{\mathrm{g}}$ of FD and EPO are practically inseparable, the binary mixture $T_{\mathrm{g}}$, if miscible, should also be between $46.65 \pm 0.44^{\circ} \mathrm{C}$ and $46.76 \pm 0.60^{\circ} \mathrm{C}$. However, although modulated DSC experiments did exhibited a single $T_{\mathrm{g}}$ for all tested FD-EPO fractions, their values did not obey the Gordon-Taylor equation. In fact, binary mixtures showed lower $T_{\mathrm{g}}$ temperatures than each individual component. It has been shown in the current literature that networking of intense hydrogen-bonding and/or electrostatic interactions between heterogeneous molecules may reduce the component mobility in the mixed region and hence result in $T_{\mathrm{g}}$ higher than those of the individual component (32). It is reasonable to suggest, in our case, that disruption of existing interaction patterns between homogeneous molecules occurred due to the presence of an added "impurity". Such disruption might have affected component mobility by increasing system entropy and hence resulted in decreased $T_{\mathrm{g}}$. It has also been shown in the literature that small amounts of moisture significantly reduce the $T_{\mathrm{g}}$; however, the likelihood of moisture presence during $T_{\mathrm{g}}$ measurement in this work is small due to heating cycle in a dry environment. Nevertheless, it was evident that the kinetically restricted region (Below $T_{\mathrm{g}}$ of dispersed system) of the constructed FD-EPO phase diagram sat in an area where temperature was lower than $46^{\circ} \mathrm{C}$. With such a low $T_{\mathrm{g}}$ temperature, it was unfeasible to extrude the FD-EPO binary mixture at any composition that would exist below the $T_{\mathrm{g}}$. Therefore, the $T_{\mathrm{g}}$ curve and the region underneath will not be discussed further in this work.

\section{Hot-melt Extrusion Using Varying Processing Parameters}

To validate our hypothesis with respect to the identification of a HME processing window using a $\mathrm{F}-\mathrm{H} \mathrm{T}-\phi$ phase diagram, FD-EPO binary mixtures with $10 \mathrm{wt} \%$ FD loading were extruded at temperatures dictated by the $\mathrm{F}-\mathrm{H}$ boundary curves and miscibility regions. Initially, three drug loadings, namely 10, 30 and $50 \mathrm{wt} \%$, were considered for HME. For the latter two, however, the intermediate region was too narrow (140 $142^{\circ} \mathrm{C}$ and $142 \sim 144^{\circ} \mathrm{C}$, respectively) and the temperature difference between the two boundary curves $\left(2^{\circ} \mathrm{C}\right)$ was deemed too small to be precisely controlled by a melt extruder in practice. FD loading of $10 \mathrm{wt} \%$, on the other hand, was shown to present well-proportioned miscibility regions in the

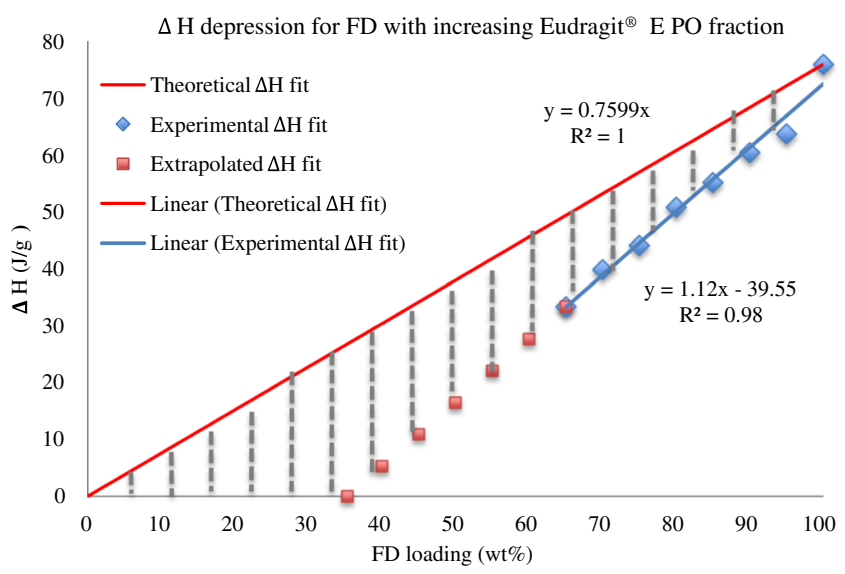

Fig. 2. Graphical representation of the $\Delta \mathrm{H}$ depression observed for FD with an increasing FD fraction. The red solid line represents the theoretical relationship between $\Delta \mathrm{H}$ and FD loading $(y=0.7599 x$, $R^{2}=1$ ), assuming no solubilisation of drug in polymer. The blue line represents the experimentally obtained $\Delta \mathrm{H}$ for predetermined FD loadings of $100,95,90,85,80,75,70$ and $65 \mathrm{wt} \%(n=3)$. The extrapolated linear relationship of $\Delta \mathrm{H}$ is based upon least square regression calculation of the experimental data $\left(y=1.12 x-39.55, R^{2}=0.98\right)$ 
Table II. Experimentally Obtained Melting Point Values and Calculated Chi Values for All Investigated FD/EPO Compositions

\begin{tabular}{lllllll}
\hline $\begin{array}{l}\mathrm{DL} \\
\text { wt } \%\end{array}$ & Volume fraction $\phi$ & $\begin{array}{l}\text { End of } T_{\mathrm{m}}(\mathrm{FD}) \\
{ }^{\circ} \mathrm{C}\end{array}$ & $\begin{array}{l}\Delta H_{\mathrm{m}}(\mathrm{FD}) \\
\mathrm{J} / \mathrm{g}\end{array}$ & $\begin{array}{l}T_{\mathrm{g}} \text { (Second heat) } \\
{ }^{\circ} \mathrm{C}\end{array}$ & $\begin{array}{l}1 / T_{\mathrm{m}} \text { (end) } \\
\mathrm{K}^{-1}\end{array}$ & $\begin{array}{l}\text { Interaction parameter } \chi \\
100\end{array}$ \\
\hline 1.00 & $145.88 \pm 0.02$ & $75.99 \pm 0.10$ & $46.65 \pm 0.44$ & $2.386 \times 10^{-3}$ & - \\
95 & 0.94 & $145.78 \pm 0.05$ & $63.70 \pm 1.70$ & $46.33 \pm 0.22$ & $2.387 \times 10^{-3}$ & 0.0396 \\
90 & 0.88 & $145.68 \pm 0.07$ & $60.42 \pm 0.92$ & $46.29 \pm 0.64$ & $2.388 \times 10^{-3}$ & 0.0870 \\
85 & 0.83 & $145.27 \pm 0.13$ & $55.14 \pm 4.83$ & $45.87 \pm 1.35$ & $2.390 \times 10^{-3}$ & 0.1939 \\
80 & 0.77 & $145.05 \pm 0.08$ & $50.81 \pm 6.27$ & $44.87 \pm 0.06$ & $2.392 \times 10^{-3}$ & 0.3004 \\
75 & 0.72 & $144.59 \pm 0.08$ & $44.08 \pm 0.53$ & $43.20 \pm 1.50$ & $2.394 \times 10^{-3}$ & 0.3179 \\
70 & 0.66 & $144.50 \pm 0.64$ & $39.84 \pm 0.63$ & $43.12 \pm 0.97$ & $2.395 \times 10^{-3}$ & 0.4244 \\
65 & 0.61 & $144.31 \pm 0.09$ & $33.40 \pm 2.72$ & $40.72 \pm 0.57$ & $2.396 \times 10^{-3}$ & 0.4916 \\
0 & 0.00 & - & - & $46.76 \pm 0.60$ & - & - \\
\hline
\end{tabular}

Values are reported as the mean \pm standard deviation of three individual samples

phase diagram and two distinctive boundary temperatures, $126^{\circ} \mathrm{C}$ and $140^{\circ} \mathrm{C}$, on the spinodal and solubility curves, respectively (Fig. 4).

Using the previously calculated $\chi$ values and the boundary temperatures for the aforementioned three FD loadings, a Gibb's free energy of mixing plot was constructed and is presented in Fig. 5. Notably, although the interaction parameter $\chi$ values calculated at all temperatures were positive indicating unfavourable FD-EPO mixing, the free energy of mixing plot exhibited negative values across the entire composition range at temperatures higher than $142^{\circ} \mathrm{C}$ (Fig. 5b). Such a result is suggesting increasingly pronounced contribution of entropy to the system miscibility at elevated temperatures. For the chosen $140^{\circ} \mathrm{C}$, the shape of $\Delta G_{\text {mix }}$ plot was sigmoidal with a negative value of $\Delta G_{\text {mix }}$ at the chosen drug loading for HME (10 wt \%), supporting thermodynamically favoured mixing at this $\mathrm{T}-\phi$ coordinate.

According to our $\mathrm{T}-\phi$ phase diagram, we anticipated that the $10 \mathrm{wt} \% \mathrm{FD}$ loaded extrudates processed at $140^{\circ} \mathrm{C}$ to show homogeneous FD molecular dispersion within the EPO matrix; those extruded at $126^{\circ} \mathrm{C}$ to attain FD amorphisation but showing instability to substantial FD density fluctuation. Another two extreme temperatures, $110^{\circ} \mathrm{C}$ and $150^{\circ} \mathrm{C}$, respectively, were also applied to extrusion processing. The former was chosen from the unstable region as a critical lower bound for processability, whilst the latter was chosen from the liquid/ miscible region for the production of a FD-EPO solid solution. Notably, such hypotheses are founded entirely on a T- $\phi$ phase diagram obtained by applying the $\mathrm{F}-\mathrm{H}$ theory to melting point depression phenomenon using thermal measurements. In doing so, it is believed that an underestimation of phase boundaries is normal in these circumstances, predicting drug-polymer miscibility as well as determining the extrusion temperature during HME processing since the mechanical energy input associated with screw agitation is neglected. In view of this, the influence of mechanical input on extrudate properties was assessed by applying varying screw speeds, 20 , 100 and $200 \mathrm{rpm}$, to each respective extrusion temperature.

It has been previously shown that increasing screw speed increases dissolution of drug into a molten carrier (19), when selected processing temperatures were all significantly below $T_{\mathrm{m}}$ of the drug. To date, there is limited information within the literature clearly stating the influence of screw speed at temperatures that would thermodynamically favour drug- polymer mixing. In addition, if the influence of screw speed differs with changes in thermodynamic conditions, the investigation of screw speed effects may aid the optimisation of the $\mathrm{HME}$ processing window predicted by a $\mathrm{F}-\mathrm{H} \mathrm{T}-\phi$ phase diagram.

Figures 6 and 7 illustrate the average residence time and processing torque, respectively, during extrusion (data presented to Table I). In agreement with literature, the average residence time decreased significantly upon elevation in both temperature and screw speed (33-35). Among all investigated temperature-screw speed $\left({ }^{\circ} \mathrm{C}-\mathrm{rpm}\right)$ combinations, $110^{\circ} \mathrm{C}$ with $20 \mathrm{rpm}$ resulted in dramatically prolonged mean residence time, approximately 3 20 folds longer than that of the others. The recorded average processing torque $(\tau)$, on the other hand, decreased with rising temperature and increased with increasing screw speed (Fig. 7). It was also observed that there was no significant difference for either residence time or torque between $140^{\circ} \mathrm{C}$ and $150^{\circ} \mathrm{C}$ for each screw speed $(P>0.05)$.

For fixed screw rotating speed (shear rate) and feed rate (throughput), a shorter residence time often indicates better flow properties of the melt, which is also suggestive of lower melt viscosity $(36,37)$. Its dependence on temperature could be easily explained using the Arrhenius equation, $\eta=\mathrm{K}^{\prime} \times e^{\frac{\mathrm{E} \alpha}{R T}}$, where $\eta$ is the melt viscosity; $\mathrm{K}^{\prime}$, a constant and $E_{\alpha}$, the activation energy, respectively, dependent upon

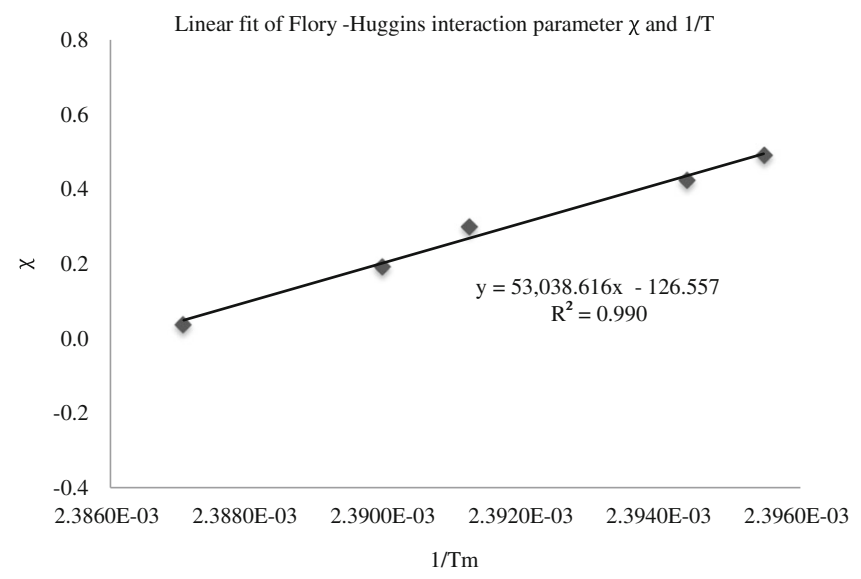

Fig. 3. Variation in Flory-Huggins interaction parameter $\chi$ as a function of temperature $(1 / T)$ 


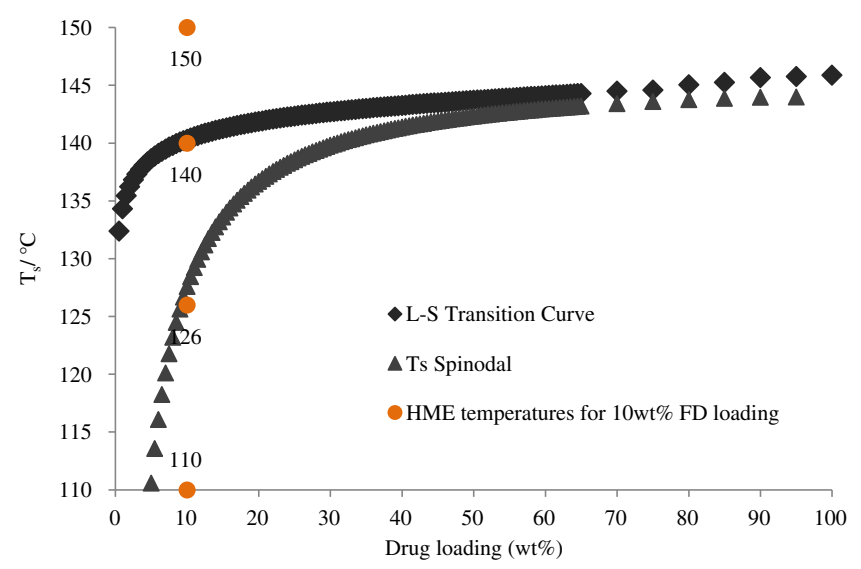

Fig. 4. The T- $\phi$ phase diagram for the FD-EPO system. ( $\diamond$ liquidsolid transition curve (solubility curve), ( $\mathbf{A})$ spinodal curve, $(\bigcirc)$ investigated HME temperatures

the type of polymer; $R$ is the gas constant, and $T$ is the measuring temperature in Kelvin (38). In this work, the polymer type and composition remained the same for all extrudates; thus, $\mathrm{K}^{\prime}$ and $\mathrm{E}_{\alpha}$ both remained constant. Therefore, elevating temperature resulted in lower viscosity, improved flow properties and hence shortened residence time. For fixed temperature and throughput, in contrast, increased screw speed typically reduces residence time through faster conveying of material to the die exit (39). The processing torque during HME is a measure of the mechanical energy input applied to the rotating screws by the motor. This energy input is typically dissipated into three aspects: screw agitation $\left(\tau_{\text {empty }}\right)$, forward material pumping $\left(\tau_{\text {pump }}\right)$ and melt shearing $\left(\tau_{\text {shear }}\right)$ (40). Therefore, the torque is essentially indicative of the resistance of the melt against the screw mechanical stresses along both axial and rotational directions. The occurrence of such resistance is often a consequence of, and directly proportional to, the melt viscosity. It is thus easy to understand that for fixed screw speed, elevated temperatures cause viscosity decrease, thus lowering processing torque. Whereas for fixed temperature, increased screw speeds consume additional mechanical energy and reflect higher $\tau_{\text {empty }}$, thus higher overall torque $(\tau)$. It is noteworthy that the increase in $\tau$ along screw speed elevation should be particularly significant at lower temperatures when the melt viscosity is higher. Simultaneously, the aggressive global motion of materials triggered by high screw rotating speed could generate frictional heat and hence result in a rise in local temperature. This local temperature rise may then reflect local viscosity fluctuations that could subsequently affect the $\tau$ readings; thus, greater standard deviations may be observed for mean torque values at higher screw speeds (41-43). Therefore, for the FD-EPO melt inside the extruder, a decrease in residence time and increase in average torque would be expected with increasing screw speed, and the same should hold true for elevations in processing temperature (35). Moreover, the similarity in the mean residence time and the torque values between $140^{\circ} \mathrm{C}$ and $150^{\circ} \mathrm{C}$ may be attributed to a similar melt viscosity of the system at these two temperatures, regardless of the applied screw speed.
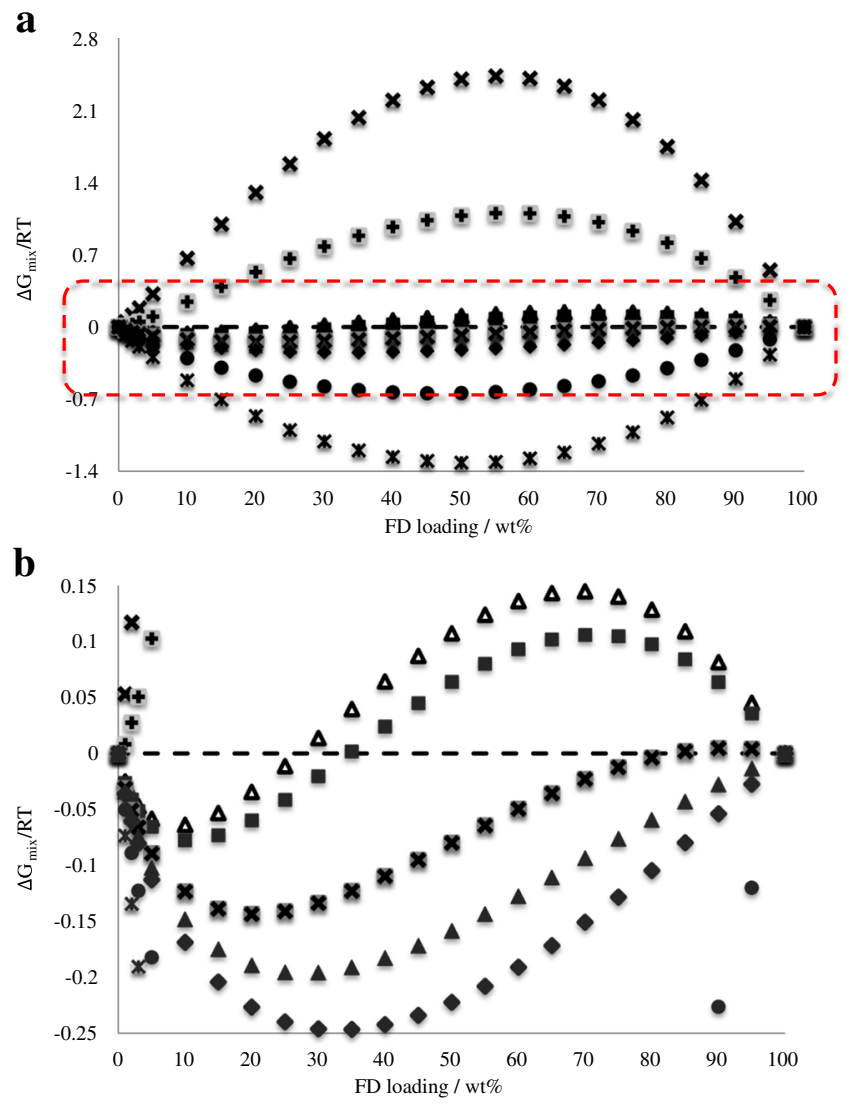

Fig. 5. Plot of $\Delta G_{\text {mix }} / R T$ versus $\mathrm{FD}$ weight fraction for FD-EPO binary system at temperatures of $(\boldsymbol{\varkappa}) 110^{\circ} \mathrm{C},(\boldsymbol{\psi}) 126^{\circ} \mathrm{C},(\boldsymbol{\Delta}) 139^{\circ} \mathrm{C}$, (ם) $140^{\circ} \mathrm{C},(\mathbf{X}) 142^{\circ} \mathrm{C},(\boldsymbol{\Delta}) 143^{\circ} \mathrm{C},(\bullet) 144^{\circ} \mathrm{C},(\bullet) 150^{\circ} \mathrm{C}$ and $(\boldsymbol{X})$ $160^{\circ} \mathrm{C}$. The lower graph (b) shows the expanded section of the red-dot circled area shown in the figure (a)

\section{Solid State Characterisation of the FD-EPO Melt Extrudates}

\section{Powder X-ray Diffraction}

Figure 8 shows powder X-ray diffractograms for representative extrudates. A PXRD pattern for a $10 \mathrm{wt} \%$ drugloaded physical mixture is provided for comparative purposes. The physical mixture exhibited diffraction peaks characteristic

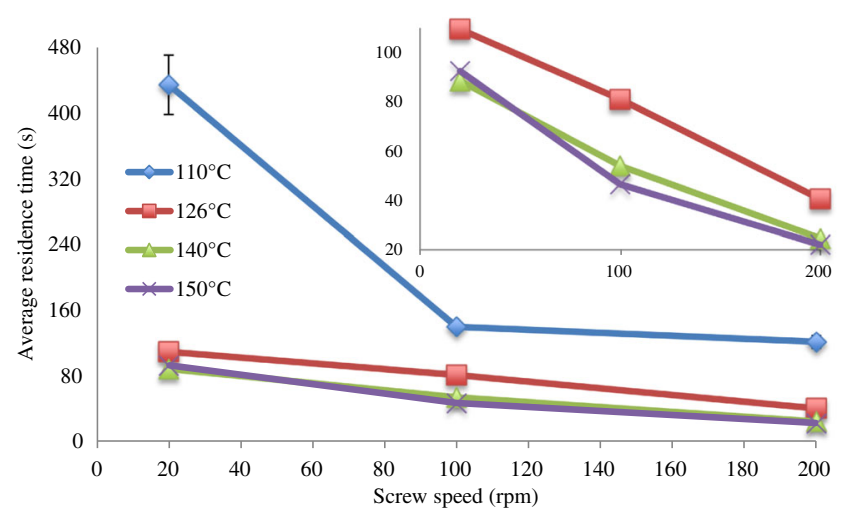

Fig. 6. Variation in the mean residence time as a function of screw speed. The values shown are the average \pm standard deviation of three replicates 


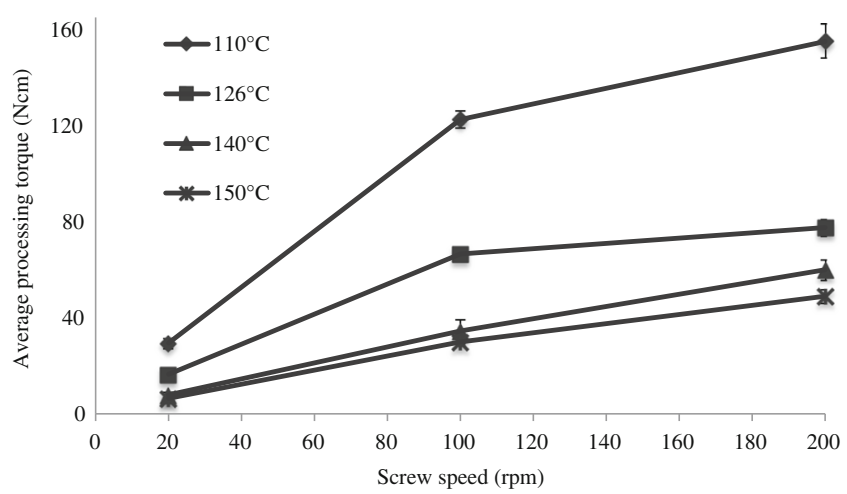

Fig. 7. Variation in the processing torque as a function of extrusion screw speed. The values shown are the average \pm standard deviation of three replicates

of crystalline FD, whereas extrudates did not display any significant diffraction peaks exhibiting a typical amorphous halo, as observed for Eudragit EPO. This suggested that melt extrudates were X-ray amorphous. Such results were not supported by visual observation as fine particulates, presumably residual crystalline FD, were embedded in the polymer matrix of extrudates manufactured at $110^{\circ} \mathrm{C}$ and $126^{\circ} \mathrm{C}$. It was possible that pre-analysis milling of extrudates rendered the remaining FD crystals in the extrudates amorphous. Alternatively, the concentration and/or the size of the remaining crystalline FD in the extruded samples were below the critical sensitivity of the technique (44).

\section{Microscopic Analyses}

Microscopy is a powerful and straightforward method to qualitatively visualise crystallinity within polymer matrix systems. Both optical and polarised light microscopes (PLM) are suitable to examine the morphology of embedded crystallites when the matrix is transparent. It is also possible to obtain reliable particle size information using these techniques (45). Figures 9 and 10 illustrate the morphology of FD-EPO extrudates processed using a range of temperatures and screw speeds. Both optical and polarised light micrographs suggested that elevation of processing temperature and increasing screw speed favoured the dissolution of FD into EPO. In particular, increasing temperature from the insoluble region $\left(110^{\circ} \mathrm{C}\right)$ to the spinodal curve $\left(126^{\circ} \mathrm{C}\right)$ significantly reduced the number of remaining crystalline particulates, whereas increasing screw speed at the spinodal temperature dramatically decreased the size of such crystallites and ultimately achieved an amorphous drug dispersion at $200 \mathrm{rpm}$. Interestingly, complete amorphisation was not achievable at $110^{\circ} \mathrm{C}$ even at extremely high screw speeds. When the temperature reached $\left(140^{\circ} \mathrm{C}\right)$ or exceeded $\left(150^{\circ} \mathrm{C}\right)$ the solubility curve, clear extrudates were observed at all three screw speeds. Notably, a few bright spots were observed in the ADD extrudates in polarised light micrographs and later confirmed to be impurities as these spots showed neither colour change whilst adjusting polarizer nor size reduction whilst being heated above $T_{\mathrm{m}}$ of FD.

\section{Raman Analysis and Mapping}

Raman maps are constructed by taking the spectra of a series of single points from a pre-determined area (typically the cross section of the sample), comparing them with that of the reference, and then plotting the correlation coefficient (using a rainbow cubic look-up table) at each coordinate. The interval between neighbouring points can be determined based upon the magnification of objective. A Raman map is most commonly presented on a rainbow-coloured lookup table where the highest correlation coefficient ' 1.00 ' is represented using the lightest colour 'white' to indicate $100 \%$ resemblance, whereas poor correlation is usually coloured as dark blue or purple. The scale of the rainbow lookup table can also be modified to distinguish the degree of similarity. As shown in Fig. 11, the Raman shift range between

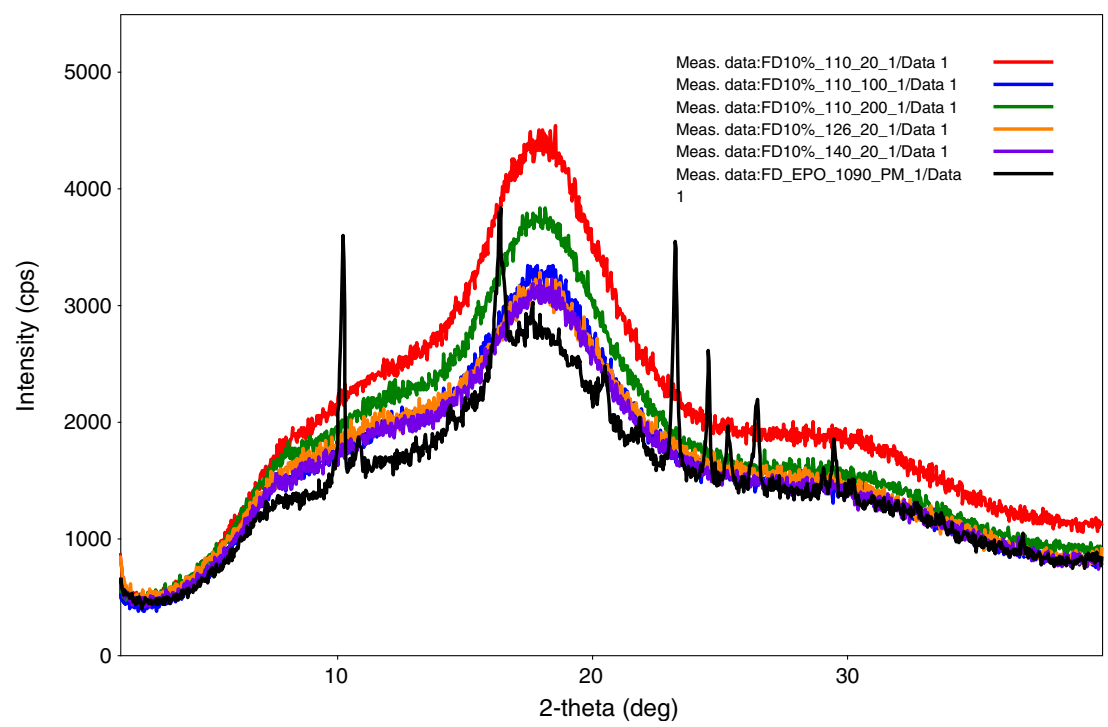

Fig. 8. Representative powder X-ray diffractograms $\left(3 \sim 40^{\circ} 2 \theta\right)$ for $10 \mathrm{wt} \%$ FD-EPO binary systems (from bottom to top): physical mixture, extrudates processed at $110^{\circ} \mathrm{C}-20 \mathrm{rpm}$, extrudates processed at $110^{\circ} \mathrm{C}-100 \mathrm{rpm}$, extrudates processed at $110^{\circ} \mathrm{C}-200 \mathrm{rpm}$, extrudates processed at $126^{\circ} \mathrm{C}-20 \mathrm{rpm}$ and extrudates processed at $140^{\circ} \mathrm{C}-20 \mathrm{rpm}$, respectively 


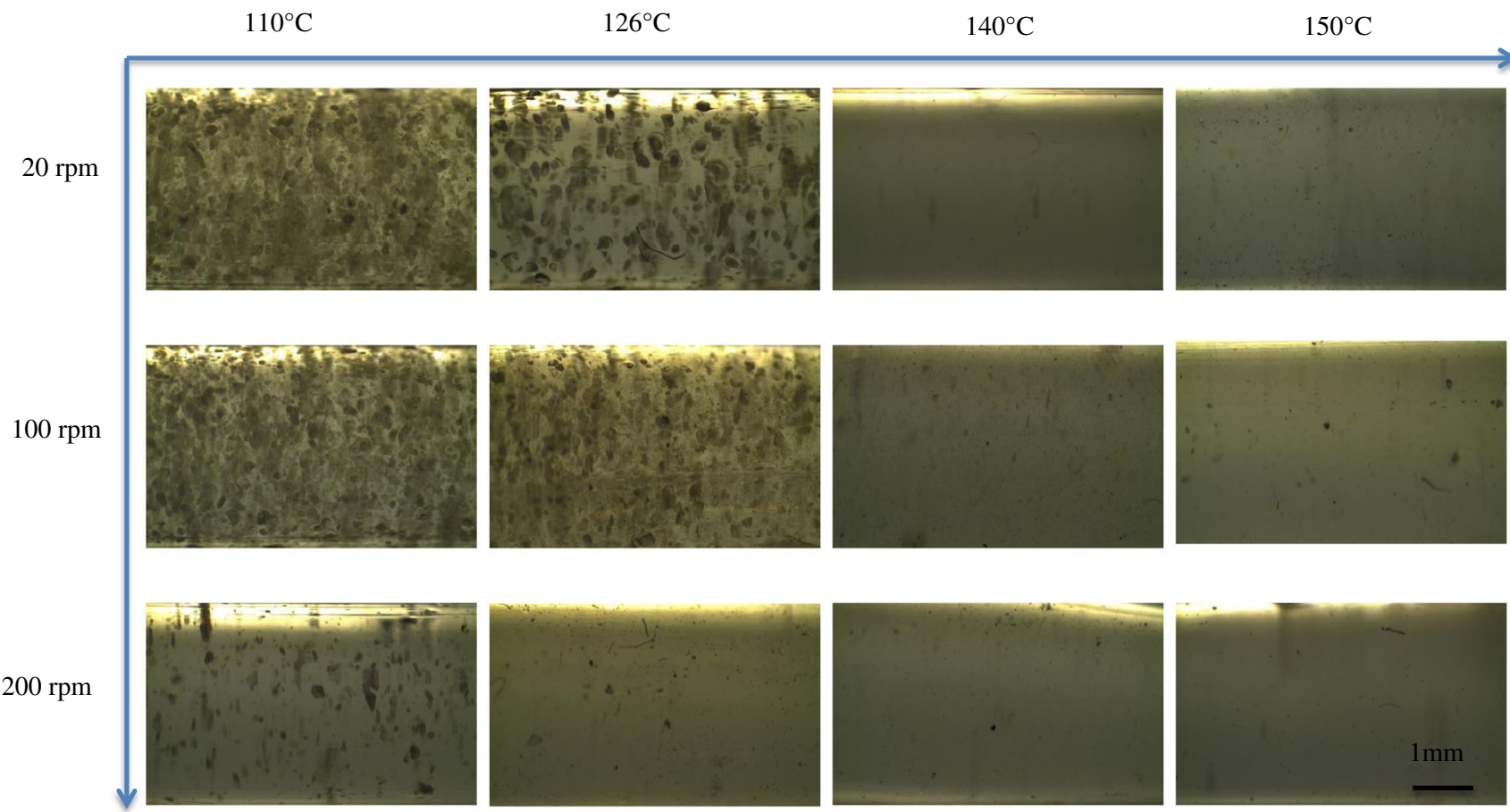

Fig. 9. Optical micrographs of a cross-sectional area of extrudates as a function of extrusion temperature and screw speed. From left to right: extruded with a barrel temperature setting of $110^{\circ} \mathrm{C}, 126^{\circ} \mathrm{C}, 140^{\circ} \mathrm{C}$ and $150^{\circ} \mathrm{C}$, respectively; and from top to bottom: processed using a screw speed of 20, 100 and $200 \mathrm{rpm}$, respectively. Images have been obtained using a $\times 25$ objective

[1720.0 1600.0 $\mathrm{cm}^{-1}$ was employed to differentiate each individual pixel in the map from the reference. In this zone, the unprocessed crystalline FD, quench-cooled amorphous FD and solvent-evaporated $10 \mathrm{wt} \%$ FD-EPO solid dispersion

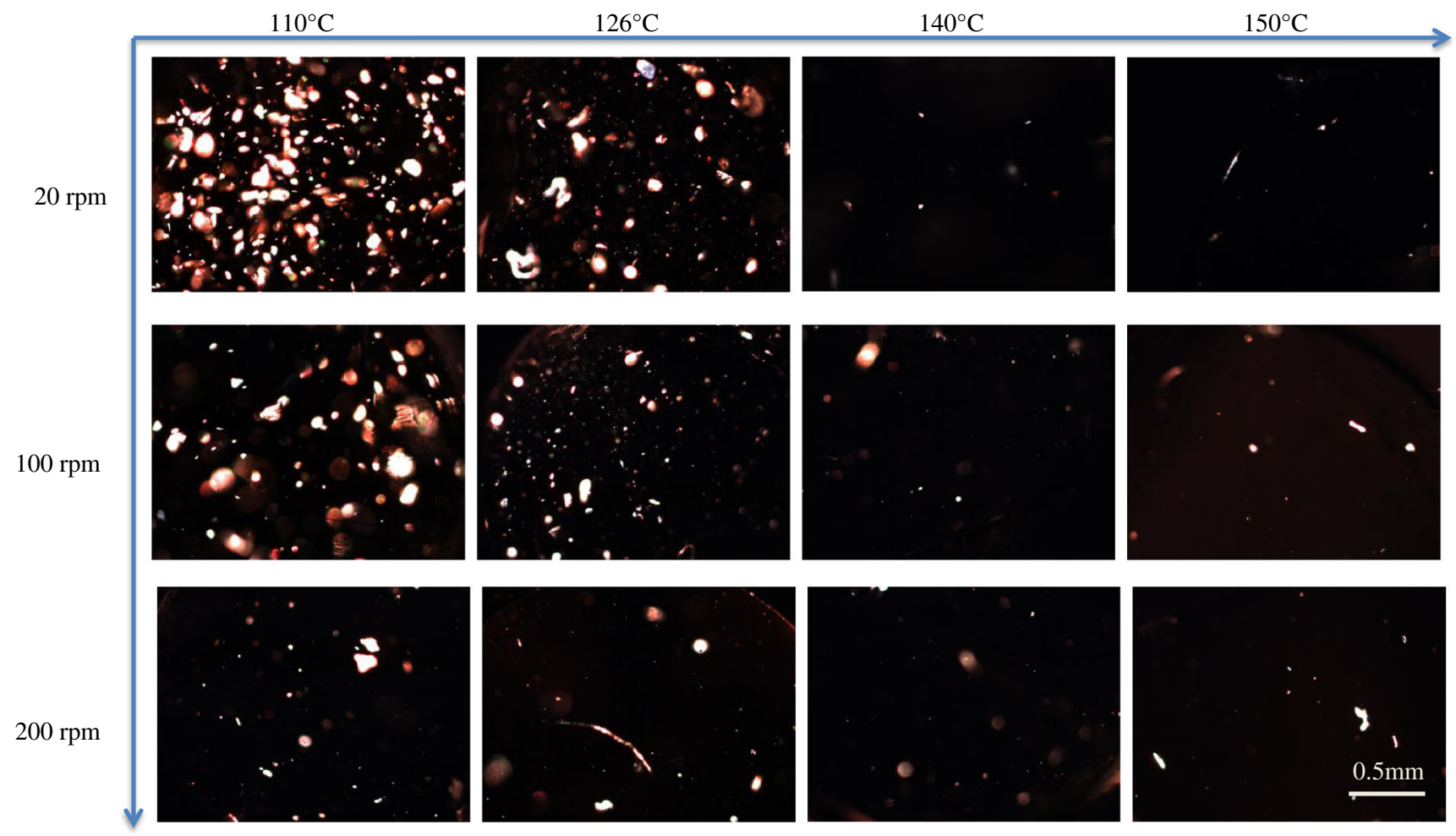

Fig. 10. Polarised light micrographs of cross-sectional areas of formulations manufactured at different temperatures and screw speeds. From left to right: formulations extruded with a barrel temperature setting of $110^{\circ} \mathrm{C}, 126^{\circ} \mathrm{C}, 140^{\circ} \mathrm{C}$ and $150^{\circ} \mathrm{C}$, respectively; processed using a screw speed of 20, 100 and $200 \mathrm{rpm}$, respectively. The micrographs were taken using a $\times 40$ objective 
(as the SD standard) showed three distinct peaks, respectively. Eudragit EPO was not spectrally active in this region exhibiting a flat baseline with no interference to the other three peaks. In general, the bands of the crystalline FD were more intense and sharper than those of the amorphous FD due to the disorganised molecular environment of the amorphous solid. The unprocessed crystalline FD peak in the chosen fingerprint region exhibited at peak at $1641.57 \mathrm{~cm}^{-1}$, indicative of a carbonyl group. The amorphous FD peak was notably broadened and moderately shifted to $1645.90 \mathrm{~cm}^{-1}$. Together with the broadening and redshift of the bonded N-H group from 3371.50 to $3334.93 \mathrm{~cm}^{-1}$ (data not shown), the interactions between $\mathrm{C}=\mathrm{O}$ and $\mathrm{N}-\mathrm{H}$ groups of $\mathrm{FD}$ molecules in the amorphous state are suggested to be stronger than that in the crystalline form $(46,47)$. In the $10 \mathrm{wt} \%$ FD-EPO SD standard, this carbonyl peak exhibited a further blue shift to $1649.36 \mathrm{~cm}^{-1}$, implying a possible bonding between heterogeneous FD and EPO molecules. The difference among the three peaks was subtle but experimentally reproducible to distinguish the physical form of FD. Figure 12 illustrates the colour associated to a range of correlation coefficients. It can be clearly observed from Fig. 12b that those correlation colours assigned to higher correlation coefficients ( pink-correlation coefficient $=0.99 \pm 0.01$; red-correlation coefficient $=0.94 \pm 0.02$ ) represent the presence of crystalline FD (strong peak at $1641.26 \mathrm{~cm}^{-1}$ ) and a small amount of the EPObonded FD (shoulder at $1649.13 \mathrm{~cm}^{-1}$ ). At a lower correlation, coefficient values $(0.90 \pm 0.01$ assigned yellow and $0.85 \pm 0.01$ assigned green) consisted of crystalline/amorphous FD blend characterised by a slight blue shifted peak at $1642.00 \mathrm{~cm}^{-1}$ and a small shoulder at $1649.13 \mathrm{~cm}^{-1}$ representative of EPObonded FD. At lower correlation coefficients $(0.78 \pm 0.02$ assigned an aqua colour), spectra contained peaks at $\sim 1642$ and $1649 \mathrm{~cm}^{-1}$. The intensity of the peak at $1649 \mathrm{~cm}^{-1}$ was more prominent in the aqua spectrum whereas the peak at $1642 \mathrm{~cm}^{-1}$ was more intense in the yellow and green spectra. In those spectra that did not correlate well with crystalline FD (correlation coefficient $=0.74 \pm 0.00$ ) signified a majority of EPO-bonded FD characterised by a peak at $1649.87 \mathrm{~cm}^{-1}$ with a subtle shoulder at $1646.10 \mathrm{~cm}^{-1}$ representative of amorphous FD. Dark blue colours blue region (correlation coefficient $=0.70 \pm 0.01$ ) were characteristic of EPO-bonded FD (single peak at $1649.21 \mathrm{~cm}^{-1}$ ).

As shown in Fig. 13, there are clear differences in the extrudates processed using a range of different screw speeds and temperatures. In general, especially for formulations processed at $110^{\circ} \mathrm{C}$ and $126^{\circ} \mathrm{C}$, data from Raman mapping correlated well with optical and PLM micrographs. In particular, it was shown that for both $140^{\circ} \mathrm{C}$ and $150^{\circ} \mathrm{C}, 20 \mathrm{rpm}$ resulted in complete FD amorphisation showing predominantly the EPO-bonded FD molecules with possibly very small amounts of amorphous FD regions. An increase in screw speed to $100 \mathrm{rpm}$ increased the amount of amorphous FDrich regions. Moreover, a further increase of screw speed to 200rpm was seen to result in more complex mixtures wherein certain regions were even suggested to contain FD in an intermediate transitioning state from pure crystalline to amorphous form. Such findings may correlate to the reduction of residence time at increased screw rotation speeds. At coordinates chosen from the miscible region and the solubility curve in the $\mathrm{F}-\mathrm{H} \mathrm{T}-\phi$ phase diagram, the dissolution of FD into EPO is expected to occur spontaneously. In other words, although an increased screw speed may significantly decrease the HME residence time and hence decrease the time provided for such dissolution, the majority of FD solubilisation in the surrounding EPO melt is thermodynamically favoured. Therefore, the influence of screw speed under these conditions may not be significant. In contrast, at coordinates chosen from the insoluble region, the FD solubilisation in EPO is thermodynamically hindered and high mechanical input is necessary and a dominant factor to facilitate the dispersion of FD crystals. Consequently, changes in screw speeds under such conditions may be extremely significant (19). Whereas for coordinates on the spinodal curve, FD amorphisation is

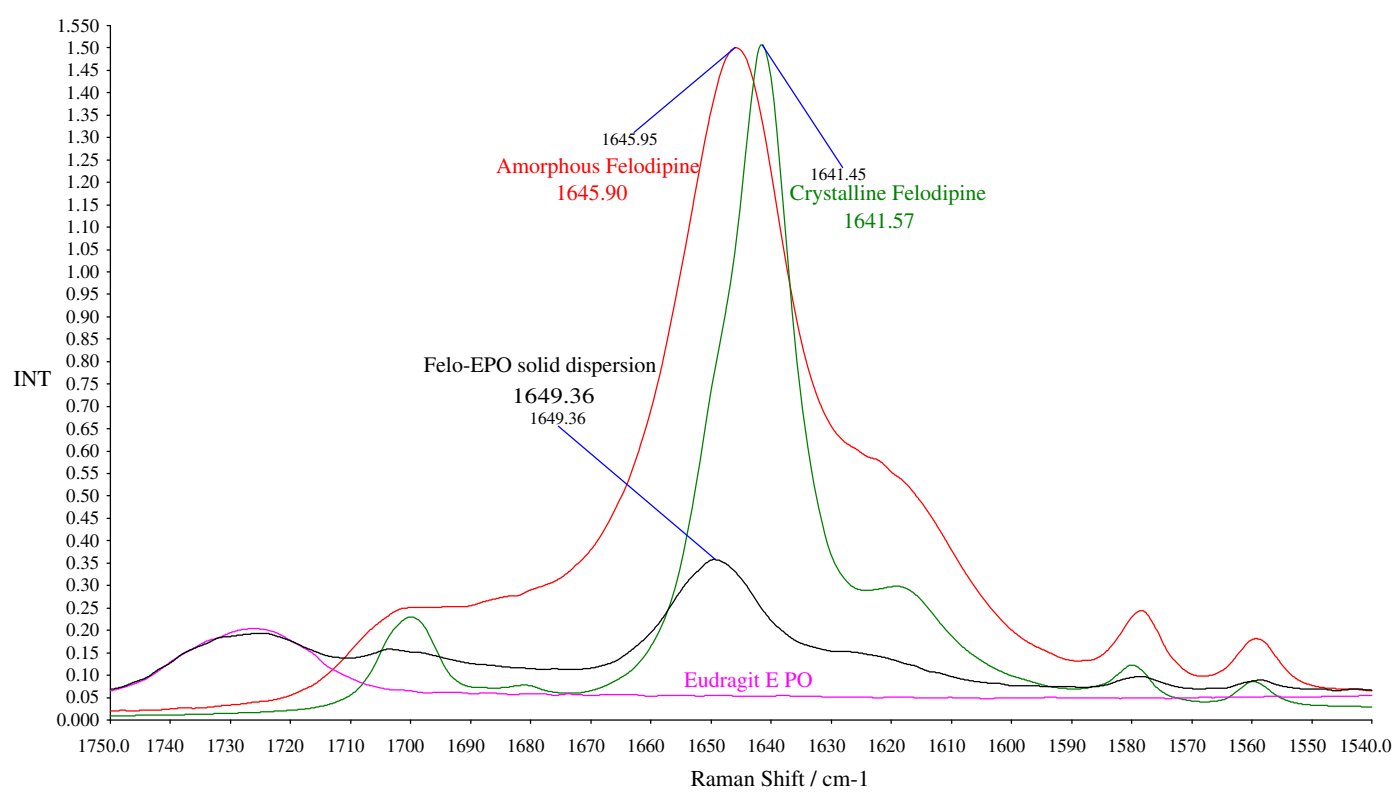

Fig. 11. Normalised partial Raman spectra of the $[1720 \sim 1600] \mathrm{cm}^{-1}$ region of the crystalline FD (green), quenchcooled amorphous FD (red), the $10 \mathrm{wt} \%$ drug-loaded FD-EPO SD prepared using solvent evaporation (black) and the excipient EPO (fuschia) 

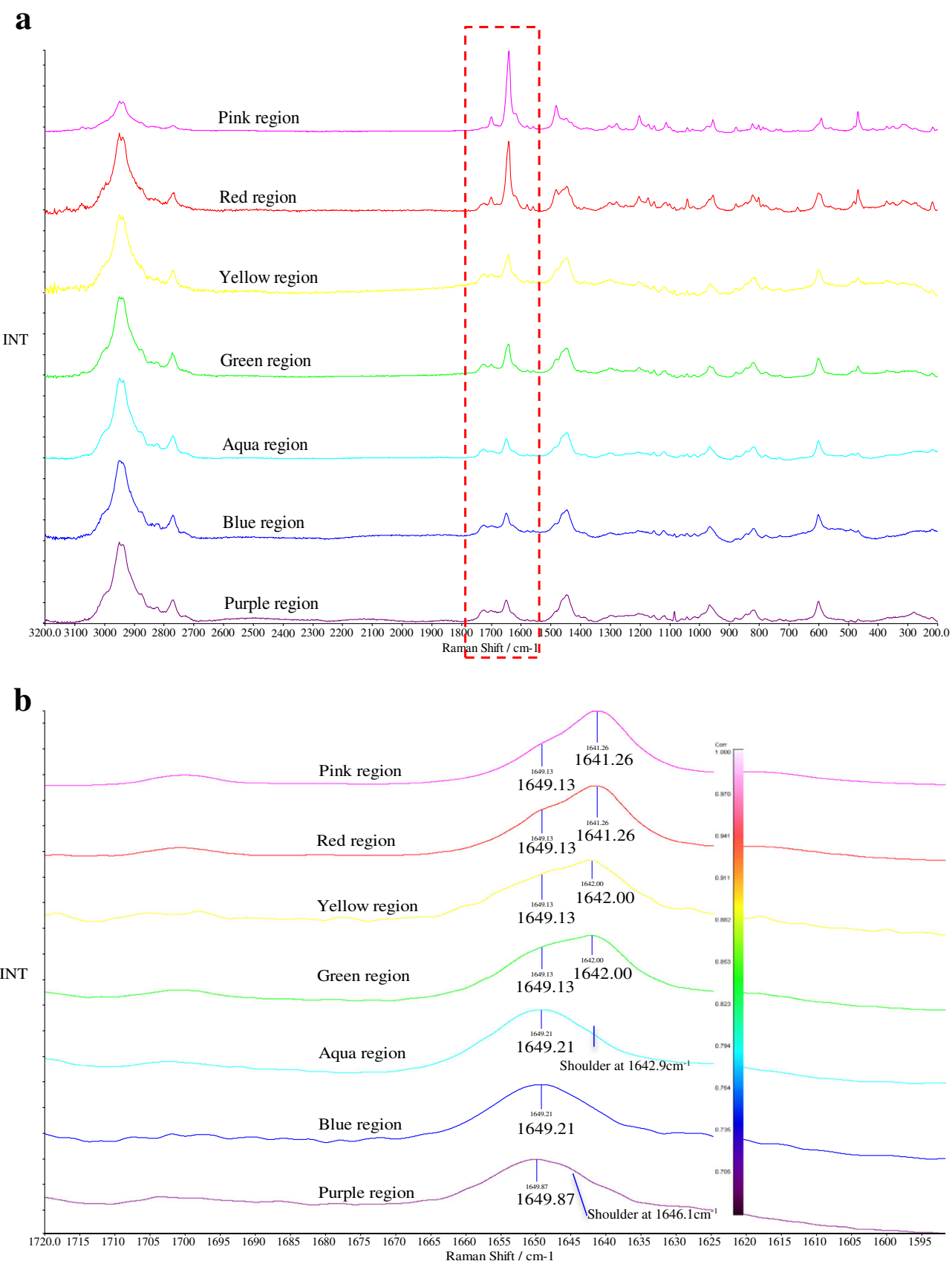

Fig. 12. a Overlay of normalised spectra exported from Raman map; b enlarged detail of partial spectra from the dashed rectangular region in a and their corresponding assigned colour in rainbow cubic look-up table

thermodynamically favoured. However, the system is sensitive to local drug density fluctuation and hence prone to considerable variations with varying shearing stress. Notably, when extruded at high temperatures and high screw speeds, the aqua region was concentrated in the centre of the extrudates, whilst the dark blue and purple coverage located more towards the exterior. This implied that the core contained $\mathrm{H}$ bonded amorphous FD-EPO (strong broad peak at $1649 \mathrm{~cm}^{-1}$ ) and residual crystalline FD (small shoulder at $1642 \mathrm{~cm}^{-1}$ ) whereas the exterior contained mostly H-bonded amorphous FD-EPO (absence of small shoulder at
$1642 \mathrm{~cm}^{-1}$ ). This is understandable as shear stress increases along the radius from the centre towards the exterior of the screw cross section. The closer the melt is to the barrel wall, more intensive the shear becomes, and hence, better mixing is achieved between FD and EPO.

\section{The Relevance of F-H Phase Diagram in Defining Design Space for HME Processing}

The manufacture of medicinal formulations with quality designed in to the product has become a strategic focus in 


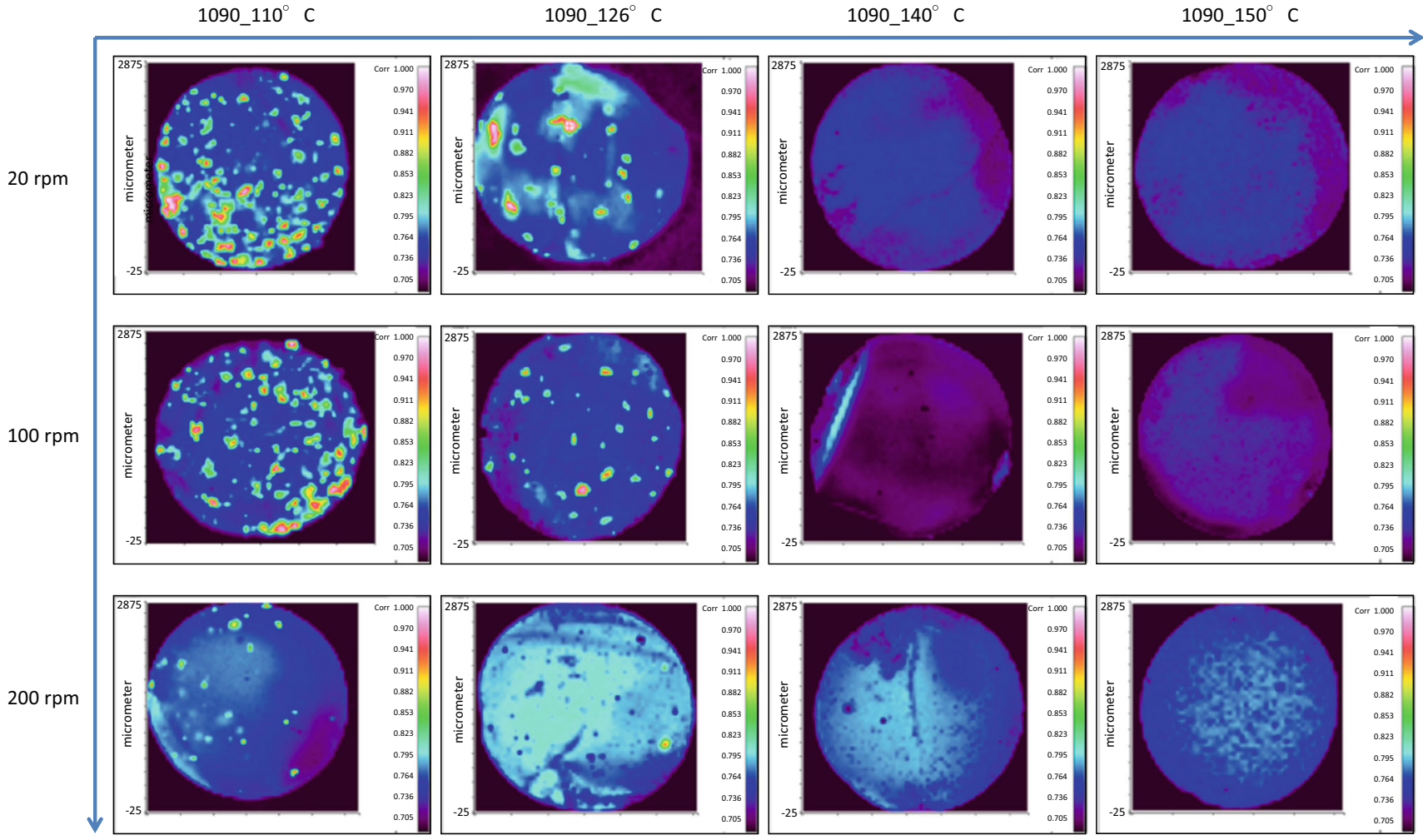

Fig. 13. Raman maps of extrudates manufactured using different extrusion parameters. From left to right: extrudates processed with a barrel temperature setting of $110^{\circ} \mathrm{C}, 126^{\circ} \mathrm{C}, 140^{\circ} \mathrm{C}$ and $150^{\circ} \mathrm{C}$, respectively; and from top to bottom: processed at a screw speed of 20,100 and $200 \mathrm{rpm}$, respectively

the pharmaceutical arena since the recent adoption of 'Quality by Design' (QbD) principles by FDA (48). The aim of implementing such principles is to design pharmaceutical products and their manufacturing processes with assured quality to meet patients' needs by delivering the intended performance. In the ICH Q8 definition, a design space is defined as the "multidimensional combination and interaction of input variables (e.g. material attributes) and process parameters that have been demonstrated to provide assurance of quality". During the course of establishing a process design space for ADD manufacture by HME, it is important to recognise that the overall objectives, namely the critical quality attributes, are sufficient drug amorphisation and minimised ingredient degradation. These are influenced by a complex interaction of several factors, such as melt temperature, shear rate, residence time and torque. The individual role of each factor is not easily defined; however, it may be understood based on controllable parameters of the process, such as barrel temperature, throughput, screw speed and screw configuration design.

For smaller-scaled HME processing, the main source of thermal energy input comes from the heated barrel, namely the temperature setting. The mechanical energy input through shearing also contributes to the elevation of local melt temperature in the form of viscous heat dissipation. A low temperature or shear will not produce sufficient mixing and thus attainment of ADD will be difficult, whilst a temperature or screw speed at the opposite extreme will result in degradation. The use of $\mathrm{F}-\mathrm{H}$ theory in combination with melting point depression measurements in previous publications by our group has been shown to provide important information relating to drug-polymer miscibility as well as providing a good approximation in terms of ranking candidate matrix polymers for ADD formulation. In this work, the information obtained from the $\mathrm{F}-\mathrm{H} \mathrm{T}-\phi$ phase diagram has been applied to examine the manufacturability of ADD. The constructed $\mathrm{T}-\phi$ phase diagram depicted the miscibility behaviour of an FD-EPO binary system. The free energy of mixing plot provided critical information such as the spontaneity of interspecies mixing/phase separation at any T- $\phi$ coordinate. Such information is particularly important when predicting the stability of an ADD under pharmaceutically relevant storage conditions. Extrudates processed using a T$\phi$ coordinate that gives a negative $\Delta G_{\text {mix }}$ at pharmaceutically relevant storage temperatures or across the entire composition range are likely to be more stable. HME experiments and solid-state characterisation confirmed that if thermal energy input is considered solely, temperatures on the liquid-solid transitioning (solubility) curve represent the lowest HME processing temperature for their corresponding drug fractions to obtain ADDs. Typically, melt extrusion processing is classified into two distinct regimes: the solubilisation regime where HME is conducted below the drug melting point and the miscibility regime in which HME is conducted above the drug melting point (49). With the application of $\mathrm{F}-\mathrm{H} \mathrm{T}-\phi$ phase diagrams, the boundary between those two regimes may be optimised to tailor any particular drug loading. The optimisation of the operational temperature may significantly enhance processing efficacy and safety without compromising product qualities. This could be especially useful in 
formulating ADD containing thermally labile drug substances. Moreover, the $\mathrm{F}-\mathrm{H} \mathrm{T}-\phi$ phase diagram may also be useful in determining the screw speed. As shown, positive effects (drug solubilisation within polymer) associated with higher screw speeds only occurred at temperatures beneath the solubility curve in the $T-\phi$ phase diagram. Such effects may be caused by a combination of increased system entropy and elevated local temperature (enthalpy). Notably, at temperatures chosen from the unstable region below the spinodal curve, complete disruption of FD crystalline structure was not achieved by increasing the screw speed. When extruded at temperatures that thermodynamically favour drug-polymer mixing, lower screw speeds should be employed to assure adequate residence time and hence complete drug amorphisation.

\section{CONCLUSION}

In this work, a F-H temperature-composition phase diagram has been constructed for a felodipine-Eudragit ${ }^{\circledR}$ EPO binary system using melting point depression data. The constructed phase diagram has been shown to be extremely informative in establishing the HME process design space for the manufacture of pharmaceutical dosage forms. Understanding the relevance between temperature and drug composition enabled the identification of an optimal HME processing temperature below the melting temperature of felodipine. This permitted complete drug-polymer dissolution even when using lower screw speeds. Such a method can be particularly useful when applied to thermally labile systems in which the instability against elevating temperature is of great concern during HME processing. The phase diagram also revealed a reasonable space where increasing screw speed, and thus shearing stress, may be employed to compensate for the lack of thermodynamic driving force for spontaneous drug-polymer solubilisation through increased system entropy.

\section{REFERENCES}

1. Fahr A, Liu X. Drug delivery strategies for poorly water-soluble drugs. Expert Opin Drug Deliv. 2007;4:403-16.

2. Laitinen R, Löbmann K, Strachan CJ, Grohganz H, Rades T. Emerging trends in the stabilization of amorphous drugs. Int $\mathrm{J}$ Pharm. 2013;453:65-79.

3. McCrum NG, Buckley CP, Bucknall CB. Principles of polymer engineering. 2nd ed. New York: Oxford University Press; 1997.

4. Rauwendaal C. Polymer extrusion. Revised 4t. München: Hanser Gardner Publications; 2001.

5. Lakshman JP, Cao Y, Kowalski J, Serajuddin ATM. Application of melt extrusion in the development of a physically and chemically stable high-energy amorphous solid dispersion of a poorly water-soluble drug. Mol Pharm. 2008;5:994-1002.

6. Keserü GM, Makara GM. The influence of lead discovery strategies on the properties of drug candidates. Nat Rev Drug Discov. 2009;8:203-12.

7. Abu-Diak O, Jones DS, Andrews GP. An investigation into the dissolution properties of celecoxib melt extrudates: understanding the role of polymer type and concentration in stabilizing supersaturated drug concentrations. Mol Pharm. 2011;8:1362-71.

8. Abu-Diak OA, Jones DS, Andrews GP. Understanding the performance of melt-extruded poly(ethylene oxide)-bicalutamide solid dispersions: characterisation of microstructural properties using thermal, spectroscopic and drug release methods. J Pharm Sci. 2012;101:200-13.
9. Song YJ et al. Physicochemical characterization of felodipinekollidon VA64 amorphous solid dispersions prepared by hotmelt extrusion. J Pharm Sci. 2013;102:1915-23.

10. Nakamichi K, Nakano T, Yasuura H, Izumi S, Kawashima Y. The role of the kneading paddle and the effects of screw revolution speed and water content on the preparation of solid dispersions using a twin-screw extruder. Int J Pharm. 2002;241:203-11.

11. Albers $\mathrm{J}$ et al. Mechanism of drug release from polymethacrylatebased extrudates and milled strands prepared by hot-melt extrusion. Eur J Pharm Biopharm. 2009;71:387-94.

12. Marsac P, Shamblin S, Taylor L. Theoretical and practical approaches for prediction of drug-polymer miscibility and solubility. Pharm Res. 2006;23:2417-26.

13. Marsac PJ, Li T, Taylor LS. Estimation of drug-polymer miscibility and solubility in amorphous solid dispersions using experimentally determined interaction parameters. Pharm Res. 2009;26:139-51.

14. Tao J, Sun Y, Zhang GGZ, Yu L. Solubility of small molecular crystals in polymers: D-mannitol in PVP, indomethacin in PVP/ VA, and nifedipine in PVP/VA. Pharm Res. 2009;26:855-64.

15. Sun Y, Tao J, Zhang GGZ, Yu L. Solubilities of crystalline drugs in polymers: an improved analytical method and comparison of solubilities of indomethacin and nifedipine in PVP, PVP/VA, and PVAc. J Pharm Sci. 2010;99:4023-31.

16. Tian YW et al. Construction of drug-polymer thermodynamic phase diagrams using Flory-Huggins interaction theory: identifying the relevance of temperature and drug weight fraction to phase separation within solid dispersions. Mol Pharm. 2013;10:236-48.

17. Tian Y, Caron V, Jones DS, Healy A-M, Andrews GP. Using Flory-Huggins phase diagrams as a pre-formulation tool for the production of amorphous solid dispersions: a comparison between hot-melt extrusion and spray drying. J Pharm Pharmacol. 2014;66:256-74.

18. Donnelly C, Tian Y, Potter C, Jones DS, Andrews GP. Probing the effects of experimental conditions on the character of drugpolymer phase diagrams constructed using Flory-Huggins theory. Pharm Res. 2015;32:167-79.

19. Liu H, Wang P, Zhang X, Shen F, Gogos CG. Effects of extrusion process parameters on the dissolution behavior of indomethacin in Eudragit ${ }^{\circledR}$ E PO solid dispersions. Int $\mathrm{J}$ Pharm. 2010;383:161-9.

20. Pajula K, Markku T, Lehto V-P, Ketolainen J, Korhonen O. Predicting the formation and stability of amorphous small molecule binary mixtures from computationally determined FloryHuggins interaction parameter and phase diagram. Mol Pharm. 2010;7:795-804.

21. Zhao YY, Inbar P, Chokshi H, Malick AW, Choi DS. Prediction of the thermal phase diagram of amorphous solid dispersions by Flory-Huggins theory. J Pharm Sci. 2011;100:3196-207.

22. Lin D, Huang Y. A thermal analysis method to predict the complete phase diagram of drug-polymer solid dispersions. Int J Pharm. 2010;399:109-15.

23. Rubinstein M, Colby R. Polymer physics. New York: Oxford University Press Inc; 2003.

24. Nishi T, Wang TT. Melting point depression and kinetic effects of cooling on crystallization in poly(vinylidene fluoride)-poly(methyl methacrylate) mixtures. Macromolecules. 1975;8:909-15.

25. Jo WH, Kwan IH. Equation of state theory for melting point depression in miscible polymer blends. Macromolecules. 1991;24:3368-72.

26. Hoei Y, Yamaura K, Matsuzawa S. A lattice treatment of crystalline solvent-amorphous polymer mixtures on melting point depression. J Phys Chem. 1992;96:10584-6.

27. Andrews GP, Zhai H, Tipping S, Jones DS. Characterisation of the thermal, spectroscopic and drug dissolution properties of mefenamic acid and polyoxyethylene? Polyoxypropylene solid dispersions. J Pharm Sci. 2009;98:4545-56.

28. Hancock BC, Shamblin S, Zografi G. Molecular mobility of amorphous pharmaceutical solids below their glass transition temperatures. Pharm Res. 1995;12:799-806.

29. Craig DQM, Royall PG, Kett VL, Hopton ML. The relevance of the amorphous state to pharmaceutical dosage forms: glassy drugs and freeze dried systems. Int J Pharm. 1999;179:179-207. 
30. Qi S et al. Characterisation and prediction of phase separation in hot-melt extruded solid dispersions: a thermal, microscopic and NMR relaxometry study. Pharm Res. 2010;27:1869-83.

31. Lever, T. Optimizing DSC experiments. In: Craig DQM, Reading M, editors. Thermal Analysis of Pharmaceuticals. Boca Raton: CRC Press Taylor \& Francis Group; 2007. 23-52.

32. Kadoya $\mathrm{S}$ et al. Glass-state amorphous salt solids formed by freeze-drying of amines and hydroxy carboxylic acids: effect of hydrogen-bonding and electrostatic interactions. Chem Pharm Bull. 2008;56:821-6.

33. Dreiblatt A. Process design. In: Ghebre-Sellassie I, Martin C, editors. Pharmaceutica extrusion technology. New York: Marcel Dekker, Inc; 2003. 140-54.

34. Thiele W. Twin-screw extrusion and screw design. In: GhebreSellassie I, Martin C, editors. Pharmaceutical extrusion technology. New York: Marcel Dekker, Inc; 2003. 69-98.

35. Nikitine C, Rodier E, Sauceau M, Fages J. Residence time distribution of a pharmaceutical grade polymer melt in a single screw extrusion process. Chem Eng Res Des. 2009;87:809-16.

36. Thompson M, Puaux JP, Hrymak AN, Hamielec AE. Modeling the residence time distribution of a non-intermeshing twin screw extruder. Int Polym Process. 1995;10:111-9.

37. Kumar A, Ganjyal GM, Jones DD, Hanna MA. Modeling residence time distribution in a twin screw extruder as a series of ideal steady-state flow reactors. J Food Eng. 2008;84:441-8.

38. Shah S, Maddineni S, Lu J, Repka MA. Melt extrusion with poorly soluble drugs. Int J Pharm. 2013;453:233-52.

39. Chokshi RJ, Zia H. Hot-melt extrusion technique: a review. Iran J Pharm Res. 2004;3:3-16.

40. Liang M, Huff HE, Hsieh F-H. Evaluating energy consumption and efficiency of a twin-screw extruder. J Food Sci. 2002;67:1803-7.
41. Lei HW, Fulcher RG, Ruan R, Van Lengerich B. Empirical modeling of die pressure, shaft torque, SME, and product temperature of rice flour in a corotating twin-screw extruder. Cereal Chem. 2005;82:582-7.

42. Das M. Effect of screw speed and plasticizer on the torque requirement in single screw extrusion of starch based plastics and their mechanical properties. Indian J Chem Technol. 2008;15:555-9.

43. Ayadi FY, Fallahi P, Rosentrater KA, Muthukumarappan K. Modeling single screw extrusion processing parameters and resulting extrudate properties of DDGS-based Nile Tilapia (Oreochromics niloticus) feeds. J Food Res. 2013;2:11-28.

44. Madsen I, Scarlett N. In: Dinnebier RE, Billinge SJL, editors. Powder diffraction, theory and practice. Cambridge: RSC Publishing; 2008.

45. Patchigolla K, Wilkinson D. Crystal shape characterisation of dry samples using microscopic and dynamic image analysis. Part Part Syst Charact. 2009;26:171-8.

46. Tang XC, Pikal MJ, Taylor LS. A spectroscopic investigation of hydrogen bond patterns in crystalline and amorphous phases in dihydropyridine calcium channel blockers. Pharm Res. 2002;19:477-83.

47. Qi S, Belton P, Nollenberger K, Gryczke A, Craig DQM. Compositional analysis of low quantities of phase separation in hot-meltextruded solid dispersions: a combined atomic force microscopy, photothermal fourier-transform infrared microspectroscopy, and localised thermal analysis approach. Pharm Res. 2011;28:2311-26.

48. Charoo NA, Shamsher AAA, Zidan AS, Rahman Z. Quality by design approach for formulation development: a case study of dispersible tablets. Int J Pharm. 2012;423:167-78.

49. DiNunzio JC, Zhang F, Martin C, McGinity JW. Melt extrusion. In: Williams III, RO, Watts AB, Miller DA, editors. Formulating poorly water soluble drugs. New York: Springer; 2012. 311-362. 